\title{
PERSEPSI GURU TERHADAP TANTANGAN DAN PELUANG PENDIDIKAN
}

\author{
Teni Husnul Khotimah \\ Pendidikan Fisika UIN Sunan Gunung Djati \\ Jl. A.H. Nasution No. 105A Bandung, \\ Email: tenihusnulkhotimah116@gmail.com \\ Natasya Siti Rokaibah \\ Pendidikan Fisika UIN Sunan Gunung Djati \\ Jl. A.H. Nasution No. 105A Bandung, \\ Email: natasyasiti2211@gmail.com \\ Suci Zahrotunnisa \\ Pendidikan Fisika UIN Sunan Gunung Djati \\ Jl. A.H. Nasution No. 105A Bandung, \\ Email: zsuci310@gmail.com \\ Muhammad Wildan Firdaus \\ Pendidikan Fisika UIN Sunan Gunung Djati \\ Jl. A.H. Nasution No. 105A Bandung, \\ Email: muhwildanf08@gmail.com \\ Rahimul Wiqi \\ Pendidikan Fisika UIN Sunan Gunung Djati \\ Jl. A.H. Nasution No. 105A Bandung, \\ Email: rahimulwiqi7@gmail.com \\ Chaerul Rochman \\ Pendidikan Fisika UIN Sunan Gunung Djati \\ Jl. A.H. Nasution No. 105A Bandung, \\ Email: Chaerulrochman@uinsgd.ac.id
}

\begin{abstract}
This study aims to determine the views of physics and non-physics teachers on the challenges and opportunities of education now and in the future, namely the entry of Indonesia in industry 4.0. Education is not a simple thing that we can ignore because basically education is the basis of the formation of a character. Countries are said to be developed if the quality of human resources possessed is high quality. In this study we used a participatory qualitative research method. The instrument used was a questionnaire response to the challenges and educational opportunities which amounted to 25 statements and was given to 10 educators in West Java. The results of this study indicate the profile of respondents' responses to educational challenges and opportunities is varied and the indicator profile of educational challenges and opportunities is at $70 \%$. This study concludes that the level of educator response to the nature of education is quite low at 70\%. The most dominant aspects of challenges and opportunities include the role of globalization and technological development. This study recommends that teachers improve the individual quality of each student and the placement of learning systems that are compatible with the education system in the era of the industrial revolution 4.0.
\end{abstract}

\section{Keywords:}

Challenge; Opportunity; Education; System; Industry 4.0. 


\begin{abstract}
Abstrak
Penelitian ini bertujuan untuk mengetahui pandangan guru fisika dan nonfisika terhadap tantangan dan peluang pendidikan saat ini dan saat mendatang yaitu masuknya indonesia pada industri 4.0. Pendidikan bukanlah hal sederhana yang bisa kita abaikan karena pada dasarnya pendidikan merupakan dasar dari terbentuknya sebuah karakter. Negara dikatakan maju bila SDM yang dimiliki berkualitas dan berkuantitas. Pada penelitian ini kami menggunakan Metode penelitian kualitatif partisipatoris. Instrumen yang digunakan adalah angket tanggapan terhadap tantangan dan peluang pendidikan yang berjumlah 25 pernyataan dan diberikan kepada 10 orang pendidik di Jawa Barat. Hasil penelitian ini menunjukkan profil tanggapan responden terhadap tantangan dan peluang pendidikan adalah bervariasi dan profil indikator tantangan dan peluang pendidikan berada pada $70 \%$. Penelitian ini menyimpulkan bahwa tingkat tanggapan pendidik terhadap hakikat pendidikan cukup rendah berada pada $70 \%$. Aspek-aspek tantangan dan peluang yang paling dominan antara lain peranan globalisasi dan perkembangan teknologi. Penelitian ini merekomendasikan agar guru meningkatkan kualitas individu setiap siswa dan penempatan sistem pembelajaran yang sesuai dengan sistem pendidikan di era revolusi industri 4.0.
\end{abstract}

Kata Kunci:

Tantangan; Peluang; Sistem; Pendidikan; Industri 4.0.

\section{A. PENDAHULUAN}

Peluang pendidikan saat ini dan saat mendatang di Indonesia sangatlah bertolak belakang dengan era revolusi industri 4.0.

Ungkapan bijak dari Nelson Mandela Education is the most powerful weapon which you can use to change the world (Helsy, dkk, 2013). Pendidikan dan peradaban manusia (human civilization) bagaikan dua telapak tangan yang mudah untuk dikendalikan. Pendidikan di satu sisi berfungsi untuk mengarahkan peradaban kehidupan melalui produk ilmu pengetahuan, teknologi dan seni. Sebaliknya dinamika peradaban manusia yang pada saatnya akan melahirkan berbagai tuntutan manusia dan hal itu dapat dipenuhi melalui upaya pendidikan. John Dewey pernah mengatakan "the schools should teach everything that anyone is interested in learning".'( Gordon, Gordon, Aber, and Berliner, 2019).

Pendidikan harus diarahkan untuk memenuhi kebutuhan manusia dalam menghadapi tantangan hidupnya. Intensitas muatan pendidikan yang mampu memberikan solusi terhadap berbagai persoalan kehidupan menjadikan ukuran relevansi pendidikan pada setiap zaman.

Pendidikan terus berakselerasi mengikuti perkembangan, kebutuhan, dan tuntutan zaman. Reorientasi hingga penyusunan kurikulum baru telah dilakukan oleh banyak negara di dunia termasuk reorientasi yang mengarah ke Education 4.0 (UNESCO, 2017).

Maka dari itu, masuknya kita pada era Industri 4.0, pendidikan juga menyesuaikan eranya, pada era milenial saat ini bisa dibilang era disrupsi teknologi dikarenakan sistem dan relasi di salah satu bidangnya akan memberikan dampak yang menyebabkan persaingan kerja semakin tinggi dan menjadi tidak linear (Ghufron, G., 2018). Pengaplikasian kecerdasan buatan atau artificial intelligence merupakan contoh salah satu karakteristik unik di era sekarang (Tjandrawinata, 2016). Oleh karena itu untuk mengimbangi dan menempatkan diri di era industri 4.0, pendidikan global menjadi penentu untuk meningkatkan kualitas sumber daya manusia yang diharapkan mampu untuk bersaing di era disrupsi saat ini.

Tujuan dari penelitian ini yaitu untuk mengetahui daya saing serta potensi tenaga pendidik pada saat ini dan saat mendatang untuk terciptanya tenaga pendidik yang berkualitas dan berkuantitas, oleh karena itu kita perlu mengetahui persepsi guru-guru dalam menyikapi dan menghadapi persaingan pada era globalisasi saat ini mengenai revolusi industri 4.0. Supaya menjadi gambaran sebuah validasi untuk kedepannya.

Karena saat ini guru tidak lagi menjadi tolak ukur dalam pendidikan, tetapi sekarang siswa juga harus menjadi tolak ukur dalam keberhasilan pendidikan, sehingga sumber daya manusia akan lebih mampu bersaing di era globalisasi saat ini (Oktarina, N., 2007).

Terciptanya pendidikan yang bermutu tidak lepas dari peran pemerintah serta indikator di dalamnya oleh karena itu kita harus mengetahui permasalahannya dan apa saja peran serta kontribusi pemerintah dalam menyikapi pendidikan di Indonesia yang telah masuk pada era disrupsi.

\section{Kesenjangan Pendidikan Di Indonesia}

Kesenjangan pendidikan di Indonesia bukan hanya sekedar berita tetapi sudah menjadi sebuah cerita tersendiri, seperti kesenjangan mutu 
pendidikan dan kesenjangan tenaga pendidik, maka dari itu ada beberapa hal yang menjadi tolak ukur keberhasilan suatu sistem pendidikan yang mampu berdaya saing dalam industri 4.0, seperti yang ditegaskan bahwa Indikator keberhasilan dalam peningkatan daya saing sumber daya manusia adalah pendidikan yang bermutu, serta melaksanakan proses pembelajaran dengan supervisi pendidikan, pelatihan, dan pendampingan guru menjadi program yang perlu dilakukan untuk meningkatkan mutu standar proses pendidikan (Atikah, S., 2019).

Kesenjangan tidak hanya terjadi pada mutu pendidikan tetapi pada tenaga pendidik dan sarana prasarana yang ada.

Terlihatnya masih ada banyak kesenjangan yang terjadi antara kota, kabupaten dan pedesaan. Jumlah tenaga pendidikan yang terdapat di sekolah perkotaan lebih banyak dibandingkan dengan sekolah di pedesaan. Rendahnya minat guru untuk mengajar di pedesaan diakibatkan oleh minimnya akses transportasi serta fasilitas sarana dan prasarana sekolah yang tidak layak, hal ini menjadi salah satu bukti bentuk ketidak merataan pendidikan di Indonesia. (Vito, B., Krisnani, H., \& Resnawaty, R, 2016).

\section{Strategi Menghadapi Revolusi Industri 4.0}

Indonesia pada Industri 4.0 atau era Industri digital ini harus disesuaikan dengan berbagai langkah yang strategis, demi membangun industri manufaktur berdaya saing internasional, Indonesia berkomitmen dengan percepatan pelaksanaan Industri 4.0 hal tersebut ditandai dengan peluncuran making Indonesia 4.0 , hal ini yang menjadi strategi Indonesia untuk mengikuti era digital.

Dengan mengaplikasikan Industri 4.0, menteri perindustrian mengharapkan aspirasi besar nasional tercapai melalui konektivitas dan digitalisasi Industri 4.0 efisiensi rantai manufaktur dan kualitas produk dapat ditingkatkan (Satya, V. E, 2018).

\section{Sistem Pendidikan Yang Kurang Mendukung}

Sistem pendidikan adalah strategi pembelajaran atau metode yang digunakan dalam proses belajar mengajar untuk tercapainya tujuan peserta didik agar dapat secara aktif mengembangkan potensi di dalam dirinya (Andrean, 2014).

Sistem pendidikan membutuhkan pembaruan untuk berteman dengan era industri 4.0. Salah satu rencana yang telah pemerintah rencanakan adalah memperkuat gerakan literasi baru sebagai pengganti gerakan literasi lama. 3 gerakan literasi baru ialah literasi digital, literasi teknologi dan literasi manusia. (Aoun, 2018).

Dalam mengatasi masalah - masalah dalam pendidikan yang terjadi di negeri kita. Pemerintah menetapkan Standar Nasional Pendidikan (SNP) yang tercantum dalam PP Nomor 19/2005 tentang SNP. Adapun isi dari SNP meliputi : Standar isi kurikulum, Standar Proses, Standar Kompetensi Lulusan, Standar Pendidik dan Tenaga Kependidikan, Standar Sarana dan Prasarana, Standar Pengelolaan, Standar Pembiayaan dan Standar Penilaian Pendidikan (Lubis, A, 2013).

\section{Tantangan dan Peluang Pendidikan saat ini dan saat mendatang}

Revolusi industri dimulai dari revolusi Industri 1.0 terjadi pada abad ke 18 melalui penemuan mesin uap, kemudian revolusi Industri 2.0 terjadi pada abad ke 19-20 melalui penggunaan listrik yang membuat biaya produksi menjadi murah, revolusi Industri 3.0 terjadi pada sekitar tahun 1970 an melalui penggunaan komputerisasi, dan revolusi Industri 4.0 sendiri terjadi pada sekitar tahun 2010an melalui rekayasa intelegensia dan internet of thing sebagai tulang punggung pergerakan dan konektivitas manusia dan mesin (Prasetyo \& Trisyanti, 2018).

Kita harus mampu menyikapi secara bijak perkembangan teknologi khususnya di era Revolusi 4.0 di bidang pendidikan saat ini. Segala perubahan ini harus menjadi pendorong bagi dunia pendidikan untuk melahirkan kreativitas, sehingga dapat menghasilkan (calon) guru yang berkualitas, profesional dan berkarakter. Maka dari itu munculah tantangan-tangan yang harus dihadapi pada era revolusi 4.0 ini khusus nya pemerintah.

Tantangan yang harus dihadapi di era revolusi 4.0 oleh pemerintah adalah Infrastruktur, keberlangsungan penerapan sistem industri digital, penerapan kurikulum KKNI yang belum terimplementasikan dengan baik (Risdianto $\mathrm{E}$, 2019). 
Dengan demikian kita harus mencari solusi atas tantangan yang akan kita hadapi untuk mempersiapkan diri pada industri digital yakni dengan memanfaatkan teknologi dan diharapkan dapat mengembangkan dan menciptakannya.

Solusi pembelajaran di industri 4.0 adalah pembelajaran dengan menerapkan model hybrid/blended learning. Dalam menerapkan pembelajaran blended learning tentunya tidak terlepas dari ketersediaan infrastruktur yang memadai seperti infrastruktur jaringan internet (Risdianto

E,

2019).

Solusi yang lainnya adalah menerapkan model pembelajaran Problem Based Learning (PBL) dengan menerapkan model pembelajaran ini, orientasi siswa dalam menyelesaikan masalah, mengorganisasikan siswa menjadi belajar, menjadi pemimpin pengalaman baik individu ataupun kelompok, mengembangkan dan menyajikan hasil karya, serta menganalisis dan mengevaluasi proses pemecahan masalah dan akhirnya dapat meningkatkan keaktifan dan hasil belajar siswa (Pramudya, dkk, 2019).

Dalam penelitian ini digunakan pendekatan desain eksperimen lemah (weak experimental design) kualitatif partisipatoris, dikatakan "lemah" karena tidak dibangun suatu kelas kontrol terhadap validitas internal. Karena alasan tersebut desain seperti ini sering diklasifikasikan sebagai non-eksperimen atau pre-eksperimen (Campbell \& Stanley, 1963), yang dikemudian hari dikategorikan sebagai quasi eksperimen (Campbell \& Stanley, 1963).

Quasi eksperimen adalah eksperimen yang memiliki pengukuran dampak, perlakuan, serta unit eksperimen namun tidak menggunakan penugasan variabel acak untuk menciptakan perbandingan dalam rangka menyimpulkan perubahan yang disebabkan perlakuan (Cook \& Campbell, 1979).

Waktu penelitian sekitar 1 hari dengan tenggat waktu yang berbeda-beda dan kami melakukannya secara langsung maupun online, karena beberapa faktor yang mengharuskan kami tidak melakukan penelitian ini secara bersamasama, oleh karenanya tempat penelitian pun berbeda-beda tetapi masih satu konteks yaitu Simple Random Sampling (Sampel Acak Sederhana) adalah guru-guru baik dari jenjang SD, SMP, dan SMA.

Penentuan subjek nya adalah kepada 2 orang guru yang mengajar fisika dan non fisika baik dari jenjang SD, SMP, dan SMA.

Teknik pengumpulan data yang kami gunakan adalah Angket/kuesioner.

Data kualitatif nya adalah gender, pengalaman mengajar dan pernyataan guru dalam kuesioner.

\begin{tabular}{l|c}
\multicolumn{1}{c}{ Gender } & Jumlah \\
\hline Laki laki & 4 \\
\hline Perempuan & 6 \\
& \\
Instrumen yang digunakan adalah kuesioner \\
an pernyataan 25 butir mengenai tantangan
\end{tabular}
dengan pernyataan 25 butir mengenai tantangan dan peluang pendidikan saat ini dan saat mendatang.

langkah-langkah penelitian, kami melakukan survei secara langsung maupun online, secara langsung kami mendatangi lokasi sekolah yang akan menjadi subjek penelitian kami dengan lokasi yang berbeda-beda, kemudian kami menanyakan kesediaan bapak/ibu guru untuk diberikan sebuah kuesioner yang berisi 25 pernyataan, terdapat dua pilihan dibacakan dan di isi secara tertulis oleh subjek, sedangkan secara online kami menggunakan media berupa aplikasi whatsapp dan email kepada subjek dengan dikirimkannya soft file kuesioner yang sama.

\section{B. HASIL DAN PEMBAHASAN}

Berdasarkan hasil pengambilan data tanggapan guru-guru tentang tantangan dan peluang pendidikan, maka diperoleh hasil sebagai berikut.

\section{Profil Responden}

Profil responden yang mengisi angket tentang aspek-aspek tantangan dan peluang dalam 
dunia pendidikan dapat ditunjukan melalui grafik 1 berikut.

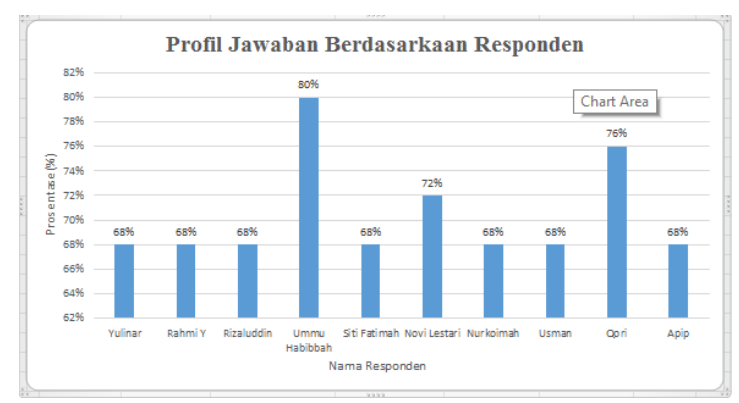

Gambar 1. Profil Jawaban berdasarkan Responden

Grafik 1 menunjukkan 10 (sepuluh) responden guru Fisika maupun lainnya yang memberikan tanggapan terhadap 25 (dua puluh lima) aspek dari tantangan dan peluang pendidikan saat ini. Prosentase rata-rata tanggapan guru adalah $70 \%$. Dari sepuluh responden yang mengisi ada satu orang guru yang memberikan pernyataan hampir sesuai dengan kondisi ideal instrumental yaitu UH (80\%). Sedangkan responden yang paling rendah tanggapannya adalah NL (72\%).

Adapun informasi tentang UH dan NL merupakan guru dengan latar belakang akademik dan pengalaman yang bervariasi. UH adalah guru Biologi wanita yang memiliki pengalaman mengajar selama 10 (sepuluh) tahun. Sedangkan NL adalah guru Kimia wanita yang memiliki pengalaman mengajar selama 3 tahun.

Berdasarkan deskripsi dan informasi di atas, maka diperoleh gambaran bahwa lamanya pengalaman mengajar guru menunjukkan perbedaan tanggapan terhadap tantangan dan peluang pendidikan. Disamping itu, meskipun guru pengampu mata pelajaran yang sama (fisika) dapat menunjukkan tanggapan yang berbeda. Antara SF dan QA tanggapan tentang tantangan dan peluang pendidikan menunjukkan hal yang berbeda (68\% dan $76 \%$ ). Sehingga diduga ada beberapa faktor yang akan mempengaruhi tanggapan guru terhadap tantangan dan peluang pendidikan di masa depan. Seperti halnya dikatakan bahwa guru saat ini menghadapi berbagai tantangan yang bersifat global (Nurhayati, 2018). Demikian juga dikatakan oleh
(Ginanjar, 2017) bahwa tantangan dan peluang tidak hanya dihadapi oleh lembaga pendidikan, tetapi juga dihadapi oleh tenaga kependidikan.

\section{Profil Tantangan dan Peluang Pendidikan}

Profil tantangan dan peluang pendidikan yang diisi oleh Responden dapat ditunjukan melalui grafik 2 berikut.

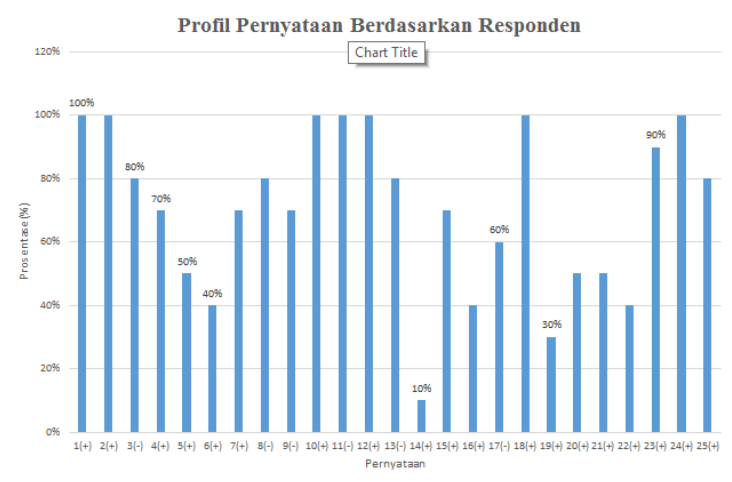

Gambar 1. Profil Pertanyataan berdasarkan Responden

Grafik 2 menunjukkan 25 (dua puluh lima) pernyataan tentang tantangan dan peluang pendidikan. Kedua puluh lima pernyataan telah ditanggapi oleh seluruh Responden yaitu 10 (sepuluh) orang responden. Dari Grafik 2 diperoleh bahwa rata-rata prosentase pernyataan sebesar 70\%. Pernyataan-pernyataan yang ditanggapi secara positif (100\%) adalah pernyataan nomor $1,2,10,12,18,24$. Sedangkan pernyataan yang paling rendah ditanggapi secara positif oleh responden adalah pernyataan nomor $14(10 \%)$.

Salah satu contoh pernyataan yang ditanggapi penuh oleh responden adalah pernyataan nomor 1 yaitu "Dengan kemajuan teknologi proses pembelajaran dapat dilakukan dengan efektif dan efisien", yang merupakan pernyataan positif (+). Semua responden tepat dalam menanggapi dari pernyataan nomor 1 ini, bahwa Teknologi sangat mempengaruhi proses pembelajaran. Sedangkan pernyataan negatif sebanyak 1 (satu buah) tentang tantangan dan peluang pendidikan saat ini ditanggapi penuh $100 \%$. Pernyataannya adalah berikut: "Kurangnya peran pemerintah dalam pendidikan untuk menghadapi industri 4.0”. 
Adapun pernyataan yang ditanggapi paling rendah oleh responden adalah: "Dengan 9 kali pergantian kurikulum pendidikan di Indonesia mengalami perubahan yang signifikan pada kualitas pendidikan". Hal ini menunjukkan responden meyakini bahwa Penggunaan teknologi dalam sistem pembelajaran pada era 4.0 merupakan faktor penentu kualitas keberhasilan pendidikan.

Berdasarkan deskripsi dan informasi di atas, maka diperoleh gambaran bahwa tantangan dan peluang pendidikan diyakini paling kuat terjadi pada aspek aspek adanya penggunaan teknologi dalam pembelajaran, pemanfaatan teknologi tugas berbasis kertas menjadi tugas online, pembelajaran memakai sistem aplikasi, membina anak didik dengan sistem pembelajaran model hybrid/blended learning agar bisa mengikuti perkembangannya, siswa malas belajar karena kecanduan sosial media dan game online, peranan organisasi, dan peranan Pemerintah. Tetapi responden menduga Teknologi sebagai faktor utama keberhasilan pendidikan saat ini.

\section{DAFTAR PUSTAKA}

Oktarina, N. (2007). Peranan Pendidikan Global dalam Meningkatkan Kualitas Sumber Daya Manusia. Dinamika Pendidikan Unnes, 2(3).

Lubis, A. (2013). Pelaksanaan Standar Nasional Dalam Dunia Pendidikan.

Andra N, C. (2014). Sistem Pendidikan. Retrieved February 4, 2019

Vito, B., dkk (2016). Kesenjangan Pendidikan Desa dan Kota. Prosiding KS, 2(2).

Ginanjar, M. H. (2017). Tantangan dan Peluang Lembaga Pendidikan Islam di Era Masyarakat Ekonomi Asean (MEA). Edukasi Islami: Jurnal Pendidikan Islam, 4(08), 17.

Nurdiansyah, N. (2017). Sumber Daya dalam Teknologi Pendidikan. Universitas Muhammadiyah Sidoarjo.

Nurhayati, N. (2018). Tantangan dan Peluang Guru Pendidikan Agama Islam di Era Globalisasi. Jurnal Ilmiah Iqra', 7(1).
Sebenarnya tidak hanya teknologi yang menjadi faktor utama dari keberhasilan pendidikan ada faktor lain seperti dinyatakan bahwa keberhasilan dan kualitas pendidikan sangat tergantung kepada manajemen kualitas prima (Ismail, (2018). Tapi Pada era 90-an teknologi pendidikan menjadi solusi pemecahan masalah dalam pendidikan (Nurdiansyah, N, 2017).

\section{C.SIMPULAN}

Tanggapan guru fisika dan lainnya terhadap tantangan dan peluang pendidikan saat ini dan saat mendatang menunjukkan variasi. Aspek-aspek, tantangan dan peluang yang paling dominan antara lain peranan globalisasi dan perkembangan teknologi. Sedangkan aspek yang perlu dipahami oleh guru adalah kualitas individu setiap siswa dan penempatan, peningkatan, serta keberlangsungannya sistem pendidikan yang baik di era revolusi industri 4.0.

Ghufron, G., 2018, September. REVOLUSI INDUSTRI 4.0: TANTANGAN, PELUANG, DAN SOLUSI BAGI DUNIA PENDIDIKAN. In Seminar Nasional dan Diskusi Panel Multidisiplin Hasil Penelitian dan Pengabdian Kepada Masyarakat 2018 (Vol. 1, No. 1).

Satya, V. E. (2018). Strategi Indonesia Menghadapi Industri 4.0. INFO Singkat.

Aoun, J. (2018). Robot-proof : higher education in the age of artificial intelligence.

Prasetyo, B., \& Trisyanti, U. (2018). REVOLUSI INDUSTRI 4.0 DAN TANTANGAN PERUBAHAN SOSIAL. In Prosiding SEMATEKSOS 3 "Strategi Pembangunan Nasional Menghadapi Revolusi Industri 4.0."

Ismail, F. (2018). Manajemen Berbasis Sekolah: Solusi Peningkatan Kualitas Pendidikan. Jurnal Ilmiah Iqra', 2(2).

Risdianto, E. (2019). Analisis Pendidikan Indonesia di Era Revolusi Industri 4.0.

Atikah, S. (2019). Peningkatan Mutu Pembelajaran Melalui Supervisi Akademik 
Berdasarkan Mutu Standar Proses Pembelajaran.

Pramudya, E., Kristin, F., \& Anugraheni, I. (2019). PENINGKATAN KEAKTIFAN DAN HASIL BELAJAR IPA PADA
PEMBELAJARAN MENGGUNAKAN

TEMATIK

PBL. NATURALISTIC: Jurnal Kajian

Penelitian

Pendidikan

dan

Pembelajaran, 3(2), 